\title{
An investigation on thermal performance of a low cost apartment in hot humid climate of Danang
}

\author{
Anh Tuan Nguyen, Sigrid Reiter
}

LEMA, University of Liège, Belgium

\begin{abstract}
Low cost apartment has recently become one of the essential state policies to deal with rapid urbanisation and population boom in Vietnam. Thermal performance of a low cost apartment in Danang was examined using building simulation approach. The simulated results created by COMFIE were first calibrated by comparing them with measured data. The statistical indicators CV(RMSE) and NMBE as well as linear regression analysis were applied to assess the calibration. The calibrated model was then used to perform whole year simulations in which various ventilation and design strategies were applied. Thermal comfort potentials of these strategies were graphically defined by Brager's adaptive comfort model from which the efficiency of each strategy was quantitatively determined. In the present paper, details of the calibration approach, assessment of simulated results and comparison of the findings were discussed. Results of these analyses revealed many notable findings which are in good agreement with those obtained from other publications. The limitation and recommendations for further study are also outlined.
\end{abstract}

Keywords : Low cost apartment ; Hot humid climate ; Building simulation ; Calibration ; Thermal comfort ; Design strategies

\section{Background and purpose of the study}

The present paper focuses on the housing issue in Danang, the biggest city in Central Vietnam with over 800,000 inhabitants. Since around 1997, the urbanisation process which is booming in Danang has raised the concern of housing issues, particularly housing for low income and poor inhabitants. In Danang, the poor are the result of many processes, such as the result of slum clearances, urban planning and rearrangement, labour immigrants, and even low income employees. Thanks to the latest housing policy of Danang according to which "everyone has the right to shelter", the city has focused on solving the housing issues from which the multistorey condominium has emerged as the most appropriate solution. Within two years, from 2009 to 2010, Danang bravely decided to build 7000 low cost apartments with $500,000 \mathrm{~m}^{2}$ floor area and these apartments have been distributed by the state [1].

However, low cost housing has been built in series with low investment rate and these housing projects were not fully investigated before groundbreaking. Consequently indoor comfort is not entirely ensured by the current designs. In any third world countries, for the homeless and the poor, having a shelter in the big city is nearly a dream of life. Therefore, residents often have many complaints about services and construction quality whereas their opinions on indoor environmental quality have not virtually been reported. However, in the near future as living standards are improving, the issue of indoor comfort will be, of course, the leading concern of these local inhabitants.

Danang has hot humid climate with which winter is always short and warm whereas summer is much longer and extremely unfavourable. In such climatic conditions, some crucial questions have emerged: (1) whether these apartments of the current design can guarantee indoor comfort; (2) which design strategies can improve thermal comfort and (3) about the efficiency and applicability of these solutions. The present paper proposed a method to evaluate thermal comfort in an apartment for low income inhabitants in Danang city and looked for design solutions to improve indoor comfort by employing calibrated simulation approach. For about 20 years, calibrated simulation approach has become a reliable tool in building simulation for general design purposes, particularly for long-term prediction or evaluation of thermal environment and energy conservation retrofits. 


\section{Details of the building and the apartment in question and measuring settings}

The selected building for the present study was located near the centre of Danang city. This 7-storey condominium is a typical design for low income residents who have been evacuated for urban slum clearance and planning elsewhere. The building was newly constructed in 2010, thus during the survey period, it was completely unoccupied. The apartment in question has gross floor area of $53 \mathrm{~m}^{2}$ with two small bedrooms and is located on the $3^{\text {rd }}$ floor at a corner of the building (see Fig. 1). The position of this apartment ensures that it is always subjected by solar irradiation in both the morning and afternoon during this survey period.

Fig. 1. The details of the selected building and apartment.

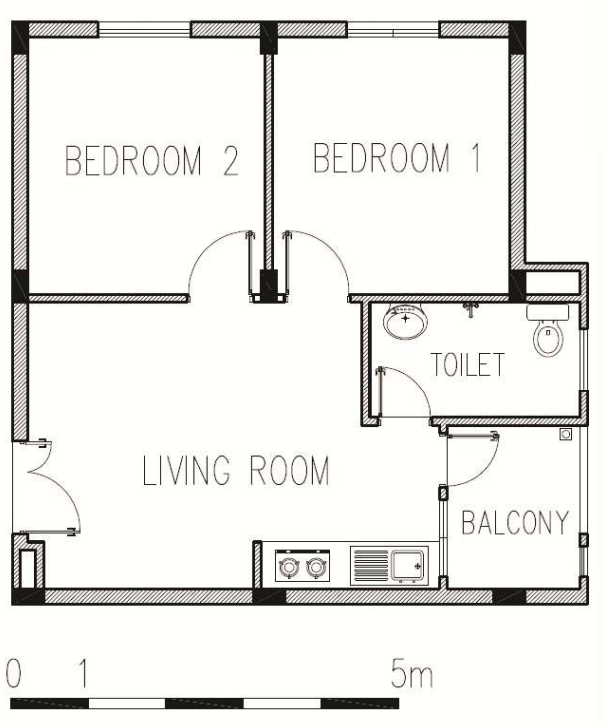

APARTMENT'S PLAN
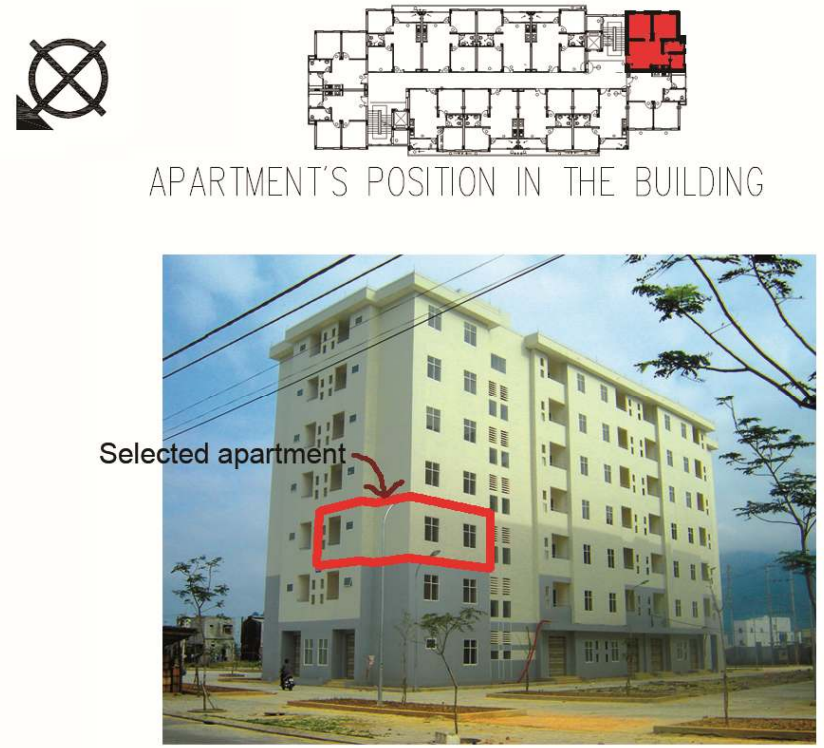

PERSPECTIVE VIEW

Air temperature and relative humidity were monitored simultaneously in the bedrooms, living room and outside (in the balcony). Such data were registered by three calibrated Extech ${ }^{\circledR}$ hygro thermometers. To ensure the accuracy of outdoor temperature measurement, the outdoor thermometer was carefully protected from surrounding radiation by a well-ventilated carton. Surface temperatures (for mean radiant temperature calculation) were recorded by Hanna HI 99550 infrared thermometer. Indoor and outdoor wind velocity were also collected using a LCA 6000 airflow anemometer. All instruments were installed in the centre of each bedroom at height of $1.10 \mathrm{~m}$ from floor level as illustrated in Table 1 . The corresponding hourly solar irradiation was derived from a National meteorological station which is not very far from the site. Heavy rain happened during the survey was also recorded. Measurement results reveal that Bedroom No. 1 (with two external walls and a window) was more sensitive to outdoor environmental changes than other rooms. For this reason, in the present paper the temperature measured in the bedroom No. 1 and solar irradiation (global and diffused) were used for the calibration purpose. Other variables are aimed to use in other studies.

Due to the limitation of measuring equipments (no data logger), these hourly environmental parameters were manually recorded from $5 \mathrm{~h}$ to $22 \mathrm{~h}$ daily. The values from $23 \mathrm{~h}$ to $4 \mathrm{~h}$ of the next day were interpolated based on the basic characteristics of local climate. The survey was carried out in 3 weeks - from 21 February to 13 March. In principle, the baseline period for calibration purpose should include the seasons and phases of the most unfavourable weather, e.g. winter and summer. However, this requires a lot of time and effort, which is, in our case, unfeasible. Three schemes of opening controls, including (1) full-day close, (2) daytime open -from $7 \mathrm{~h}$ to $19 \mathrm{~h}$ and (3) full-day open, were respectively employed in three monitored weeks.

Table 1 Technical specifications of measuring instruments. 


\begin{tabular}{|c|c|c|c|c|c|}
\hline Measuring variables & Name of instrument & Measurement range & Resolution & Accuracy & $\begin{array}{c}\text { Country of } \\
\text { origin }\end{array}$ \\
\hline $\begin{array}{l}\text { Temperature and } \\
\text { humidity }\end{array}$ & $\begin{array}{l}\text { Extech } 445702 \text { Hygro- } \\
\text { thermometer }\end{array}$ & $10-85 \%-10$ to $60^{\circ} \mathrm{C}$ & $0.1^{\circ} \mathrm{C}$ and $1 \%$ & $\pm 6 \%$ and $\pm 1^{\circ} \mathrm{C}$ & U.S.A. \\
\hline $\begin{array}{l}\text { Mean radiant } \\
\text { temperature }\end{array}$ & $\begin{array}{c}\text { Hanna Infrared } \\
\text { thermometer HI } 9950\end{array}$ & -10 to $300^{\circ} \mathrm{C}$ & $1^{\circ} \mathrm{C}$ & $\pm 2 \%$ of reading or $\pm 2^{\circ} \mathrm{C}$ & Romania \\
\hline Wind velocity & $\begin{array}{l}\text { Air flow anemometer } \\
\text { LCA } 6000\end{array}$ & $0.1-20 \mathrm{~m} / \mathrm{s}$ & $0.01 \mathrm{~m} / \mathrm{s}$ & $\pm 1 \%$ of reading or \pm 1 digit & U.K. \\
\hline
\end{tabular}

\section{Calibration approach, method and calibration results}

\subsection{Calibration approach}

Calibration of simulation programme with measured data has been recognized as an important factor in substantiating how well the model fits the data from a real building. In this case, to analyze the overall thermal performance of the case-study apartment, the simulated indoor temperature during the baseline period was compared against the average measured temperature to judge how successful the simulation was. The calibrated model will be then used to evaluate long-term building thermal performance without carrying out so many in situ measurements.

A calibration procedure normally includes several stages. First, site specific hourly data of a baseline period must be carefully collected to create a suitable weather input. The weather data are then joined into a single datafile and packed onto a TRY weather tape [2] for use with the COMFIE simulation program. Second, the calibration procedure requires a COMFIE input model based on information obtained from site visit and architectural asbuilt plans. The simulated results are finally extracted and compared with measured values to assess the "goodness-of-fit". The model is declared "calibrated" if the residual reaches an acceptable value defined in some standards $[3,4]$. An overall summary of the present calibration is illustrated in Fig. 2.

In a thermal simulation of naturally ventilated buildings, openings control and ventilation flow rate are very important input variables which crucially influence the indoor thermal environment. However, they strongly depend on natural wind, occupants, building design and quality and thus are difficult to identify. In such case, calibration approach will generate a reasonably accurate input which is useful for the whole year simulation.

Fig. 2. The creation of TRY weather file and calibration procedure of this study.

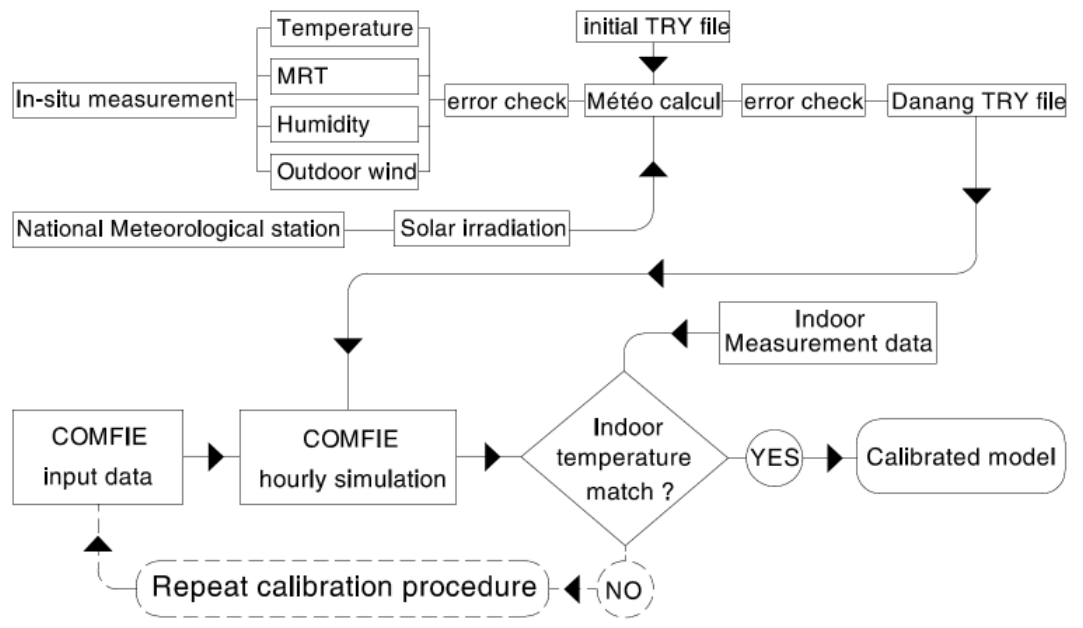

\subsection{Criteria to assess the agreement between simulated and measured data}

As summarised by Bou-Saada and Harberl [5], in many previous studies some methods have been proposed to 
verify the "goodness-of-fit" between simulated and measured data. For example, the graphical method was useful for determining where simulated results differ from measured data and some appropriate modifications to the model can be applied.

So far, it is generally accepted that statistical approach which applies two statistical indicators - Normalised Mean Bias Error (NMBE) and Coefficient of Variation of Root Square Mean Error CV(RMSE) - has become the most reliable measure to verify the calibration. The statistical approach has been adopted in some calibration guidelines, e.g. ASHRAE guideline 14-2002 [4] and ASHRAE Handbook of Fundamentals [3] and can be defined as follows:

NMBE (Normalised Mean Bias Error):

$$
\operatorname{NMBE}(\%)=\frac{\sum_{i=1}^{n}\left(t_{i p}-t_{i m}\right)}{n-1} \times \frac{1}{\overline{t_{m}}} \times 100
$$

where $t_{i p}$ is the ith predicted temperature by the simulation, $t_{i m}$ is the $i$ th measured temperature, $t_{m}$ is the arithmetic mean of the sample of $n$ measurements and $n$ is the number of data points (temperature) in the measurement.

A positive value of NMBE shows an over-estimate while a negative value indicates an under-estimate by the model. Ideally a zero value of NMBE should be obtained.

CV(RMSE) (Coefficient of variation of Root square mean error):

$$
\mathrm{CV}(\operatorname{RMSE})(\%)=\sqrt{\frac{\sum_{i=1}^{n}\left(t_{i p}-t_{i m}\right)^{2}}{n-1}} \times \frac{1}{t_{m}} \times 100
$$

$\mathrm{CV}(\mathrm{RMSE})$ is a frequently-used measure of the differences between values predicted by a model or an estimator and the values actually observed from the thing being modelled or estimated. The CV(RMSE) is always positive and a zero value is ideal.

The value of NMBE represents the systematic error or bias while the CV(RMSE) is a strong indicator of accuracy. A simulation with a small CV(RMSE), but with a significant NMBE, might indicate an error in simulation inputs. A simulation with a large CV(RMSE) but a small NMBE, might have no errors in simulation inputs, but building performance may reflect some other unmodelled behaviour (such as occupant behaviour) that is difficult to simulate [6].

In this study, the above-mentioned statistical approach was combined with a linear regression analysis as discussed in the next section to fully assess the change made after each calibration run.

\subsection{Calibration runs}

The simulation programme used in the calibration was the commercial code PLEIADES-COMFIE [7]. COMFIE's performance was validated by Peuportier [8] by comparing simulation results with those of similar tools like DOE2, TRNSYS, TAS, SIMULA, CODYBA, confirming its accuracy in thermal prediction.

In reality, about 30 iterations were completely run. Due to space constraints, only seven most significant runs were reported. Table 2 summarises the results of the entire calibration process, from the first run to the final calibrated run where simulated temperatures relatively matched with measured temperatures. The major changes made to the COMFIE input file are also listed, along with their resultant NMBE and CV(RMSE). Since the building was unoccupied during the survey, the internal heat gain by human occupancy and equipments was ignored. During calibration process, it was found that adiabatic model gave more reasonable results. Major input variables of run \#7 are presented in Appendix A.

The improvement of the "goodness-of-fit" between the simulated and the measured temperature in the apartment after each run was graphically presented in Fig. 3 (For reason of clarity, only run \#1, 3, 5, 7 were presented). This figure was very helpful in determining where the difference occurs and which modifications to the model should be applied. Fig. 3 demonstrates that only small differences existed in the run \#7. 
The tuning progress of seven calibration runs was illustrated in Fig. 4 using statistical indicators and linear regression. Fig. 4(left) demonstrates that as the calibrations proceed, the total residual in terms of the CV(RMSE) was gradually reduced and the average deviations from the mean (NMBE) approached zero. Runs \#1, 2, 3 and 4 reduced the CV(RMSE) and forced the NMBE to be negative. Runs \#5, 6 and 7 had a small improvement in the NMBE and mostly aimed to improve the CV(RMSE). At the final run, The CV(RMSE) was reduced to $2.32 \%$, and the NMBE reduced to $-0.38 \%$. These figures are statistically excellent compared with ASHRAE guideline 14-2002 [4] and ASHRAE Handbook [3]. ASHRAE [3] recommended an empirical validation using the normalised mean square error (NMSE) which is similar to CV(RMSE) and this should be less than 0.25 (or $25 \%)$. Further simulation cannot reach a smaller CV(RSME) since the present simulation assumed the same average values of air exchange rate for a series of time-steps.

In reality, air exchange rate would continuously vary according to the wind condition. If further improvement is required, we believe that specific ventilation flow rates must be applied for each time-step that would be very time consuming and unpractical.

Another method is to use the linear regression analysis to graphically assess the accuracy and correlation, which was also presented in Fig. 4(right). The correlation coefficient $\left(R^{2}\right)$ of the final predictions versus measurements of 0.927 and the linear slope of 0.872 are sufficient comparing with recommendation of ASHRAE [3] $\left(R^{2}\right.$ of 0.9 or greater and slope between 0.75 and 1.25 ).

Table 2 Summary of seven calibration runs.

\begin{tabular}{|c|c|c|c|c|}
\hline Run & Adiabatic? $^{\mathrm{a}}$ & Major changes made to model & NMBE & CV(RMSE) \\
\hline$\# 1$ & No & $\begin{array}{c}\text { Base model with simple ventilation scheme. Adjacent } \\
\text { zones of the apartment were considered full-day closed. } \\
\text { The staircase was full-day opened }\end{array}$ & $2.39 \%$ & $4.36 \%$ \\
\hline$\# 2$ & No & $\begin{array}{c}\text { Adjusted maximum ventilation flow rate from } 324 \text { to } \\
648 \mathrm{~m}^{3} / \mathrm{h} \text { Doubled ventilation flow rate during night } \\
\text { time }\left(22.7 \mathrm{~m}^{3} / \mathrm{h}\right)\end{array}$ & $2.10 \%$ & $4.51 \%$ \\
\hline$\# 3$ & Yes & $\begin{array}{l}\text { Maximum flow rate was changed to } 10 \text { ACHs. } \\
\text { Ventilation scheme was simplified Adjusted the } \\
\text { thermal resistance of brick used in the external wall } \\
\text { from } 0.16 \text { to } 0.33 \mathrm{~m}^{2} \mathrm{~K} / \mathrm{W}\end{array}$ & $1.45 \%$ & $3.34 \%$ \\
\hline$\# 4$ & No & $\begin{array}{l}\text { Tripled ventilation flow rate of the balcony to equalise } \\
\text { balcony temperature with the outdoor } \\
\text { Adjusted maximum ventilation flow rate from } 648 \mathrm{~m}^{3} / \mathrm{h} \\
\text { to } 1296 \mathrm{~m}^{3} / \mathrm{h}\end{array}$ & $-0.49 \%$ & $3.32 \%$ \\
\hline$\# 5$ & No & $\begin{array}{l}\text { Adjusted ventilation scheme to reduce disparities of } \\
\text { flow rate between adjacent time-steps }\end{array}$ & $-0.29 \%$ & $2.91 \%$ \\
\hline \#6 & Yes & $\begin{array}{c}\text { Continued adjusting ventilation scheme to reduce } \\
\text { disparities of flow rate between adjacent time-steps } \\
\text { Added the cooling effect of the heavy rain in 3, } 4 \text { and } 7 \\
\text { March }\end{array}$ & $-0.49 \%$ & $2.31 \%$ \\
\hline \#7 & Yes & $\begin{array}{l}\text { Adjusted thermal resistance of all internal doors and } \\
\text { windows }\end{array}$ & $-0.38 \%$ & $2.32 \%$ \\
\hline
\end{tabular}


Fig. 3. Comparison between simulated and measured temperature in the bedroom 1.

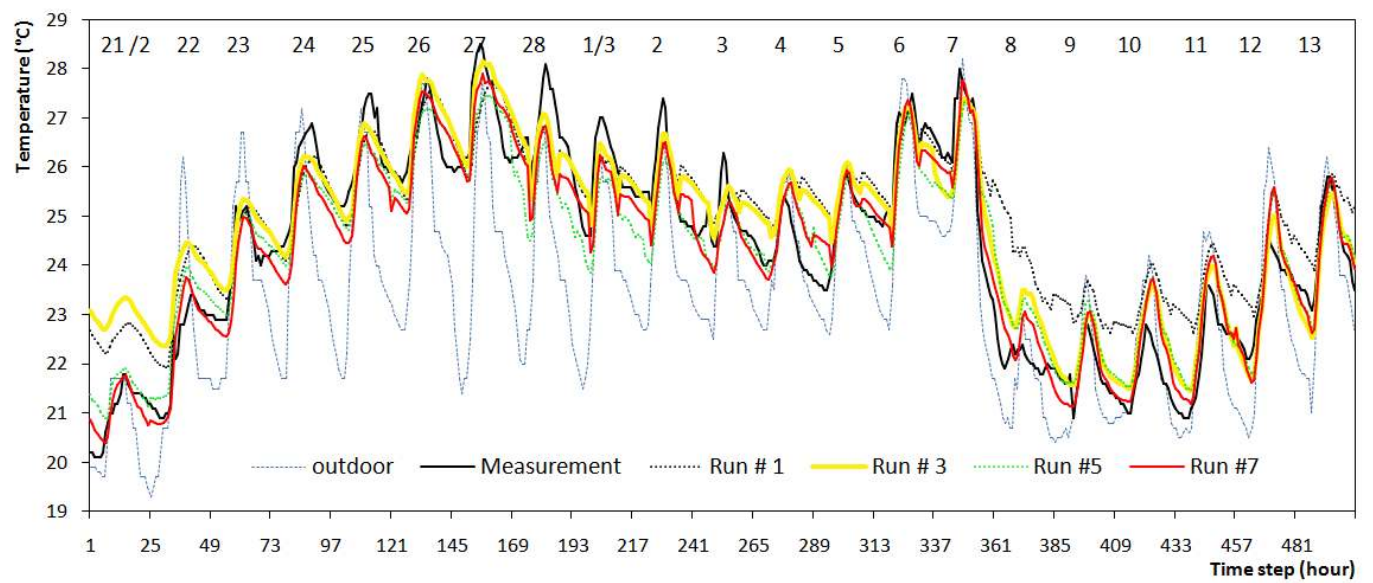

Fig. 4. Tuning progress with input modification (left) and linear regression analysis of run \#1 vs. run \#7 (right).
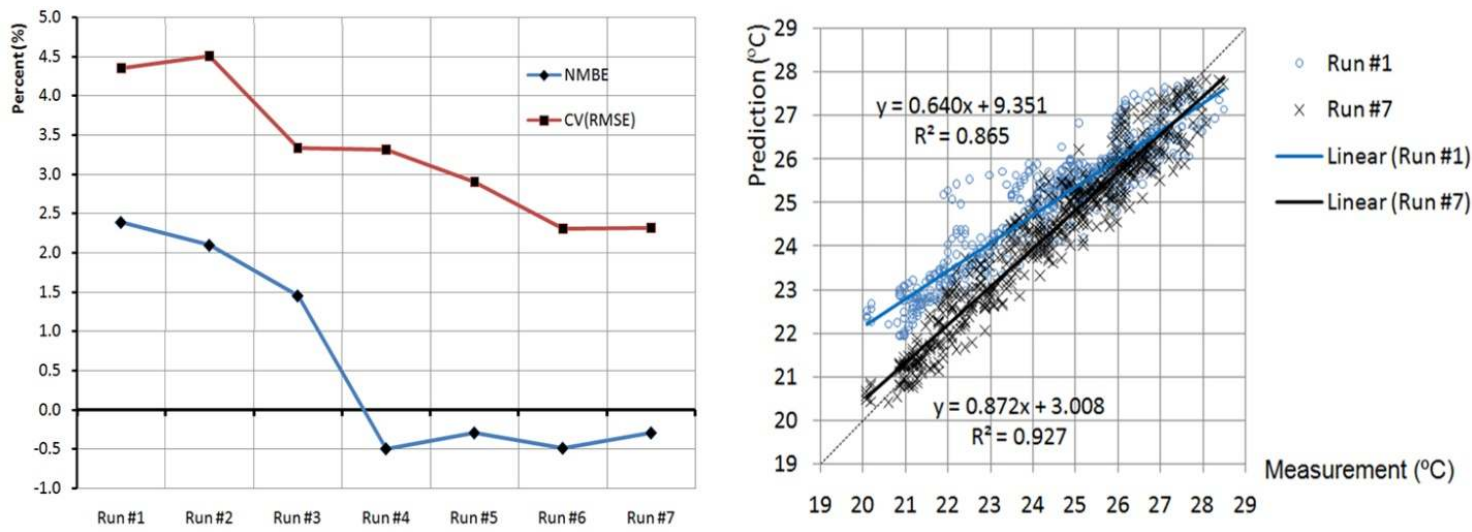

Table 3 Ventilation scenarios of the reference case.

\begin{tabular}{lccc}
\hline Season & Opening control & Maximum flow rate $\left(\mathrm{m}^{3} / \mathrm{h}\right)$ & Period applied \\
\hline Summer & Full-day open & 1269 & 30 April-30 September \\
Winter & Full-day close & 162 & 5 November-4 March \\
Mild seasons & Daytime open & 777.6 & The remaining of the year \\
\hline
\end{tabular}

\section{The effect of different strategies on indoor thermal environment using calibrated model}

\subsection{Reference case and its analysis}

First, a whole year simulation was conducted as a reference case. All simulation parameters of the abovementioned calibrated model were reused in this reference simulation. Three ventilation scenarios which correspond to three typical weather conditions (summer, winter and mild seasons) were adopted as well. The volumetric flow rates were derived from calibrated model. Details of ventilation scenarios are shown in Table 3. In this stage, the apartment was assumed to be occupied by a standard family of 4 persons and its occupancy is specified in detail at each time-step.

Thermal environment in the bedroom of this apartment was examined by plotting hourly simulated indoor temperature as a function of outdoor temperature. The adaptive comfort model proposed by Brager [9] was then superimposed to calculate and analyze comfort and discomfort period. This comfort model was proposed for comfort assessment in naturally ventilated buildings based on the results of ASHRAE RP-884 project [10] and is 
slightly different from the one published by current ASHRAE 55 standard [11]. The Brager's comfort zone is a band of $5{ }^{\circ} \mathrm{C}$ width ( $90 \%$ occupants' acceptability) which upper boundaries are defined as:

$$
T_{\text {upper }}=\left\{\begin{array}{ll}
22^{\circ} \mathrm{C} & \text { for }\left(T_{\text {out }}<5^{\circ} \mathrm{C}\right) \\
0.321 \times T_{\text {out }}+20.4 & \text { for }\left(5^{\circ} \mathrm{C} \leq T_{\text {out }} \leq 33^{\circ} \mathrm{C}\right) \\
31^{\circ} \mathrm{C} & \text { for }\left(T_{\text {out }}>33^{\circ} \mathrm{C}\right)
\end{array}\right\}
$$

where $T_{\text {upper }}$ is the upper limit temperature of comfort zone band; $T_{\text {out }}$ is the mean outdoor temperature (or monthly mean outdoor temperate). The reason that Brager's comfort model was selected instead of ASHRAE standard 55 is its capability to predict comfort temperature when outdoor temperature exceeds $33{ }^{\circ} \mathrm{C}$.

The potential comfort of the climate was examined using TRY file of Danang and Brager's comfort model as shown in Fig. 5. The comfort zone which is defined by monthly average temperature (from TRY file) is limited by two blue curves. Fig. 5 shows that Danang has a very hot summer (from May to September) during which daytime temperature far exceeds from the comfort zone. Fortunately, temperature mainly falls into the comfort zone during night time, revealing that night ventilation maybe applied. Besides, discomfort caused by cold weather is not serious and maybe easily compensated by internal heat gain because outdoor temperature never falls below $16^{\circ} \mathrm{C}$. Naturally, about half of the year is considered comfortable.

Simulated result of reference case shown in Fig. 6 reveals that for $61.63 \%$ of a year indoor temperature was considered acceptable. This performance is fairly low compared with outdoor natural comfort discussed above. A clear trend of temperature distribution was also found, revealing that major part of uncomfortable period dropped in warm and hot zone whereas only $30 \mathrm{~h}$ were considered slightly cold.

Further analyses need to be done to clarify the uncomfortable period. The fluctuations of bedroom temperature and outdoor ambient temperature during summer were simultaneously examined. We found that bedroom temperature in summer were too high during daytime and failed to decrease at night when outdoor ambient temperature significantly dropped. Two things can be derived from this phenomenon. First, during daytime the ventilation flow rate may be too high or (and) the building envelope was not well-insulated. This caused a minor difference between indoor and outdoor temperature. Second, ventilation flow rate during night time was not sufficient to cool off the internal surfaces and structures. These predictions become useful hints which reveal necessary modifications to the model to improve indoor thermal comfort.

Fig. 5. The potential thermal comfort and discomfort of Danang climate.

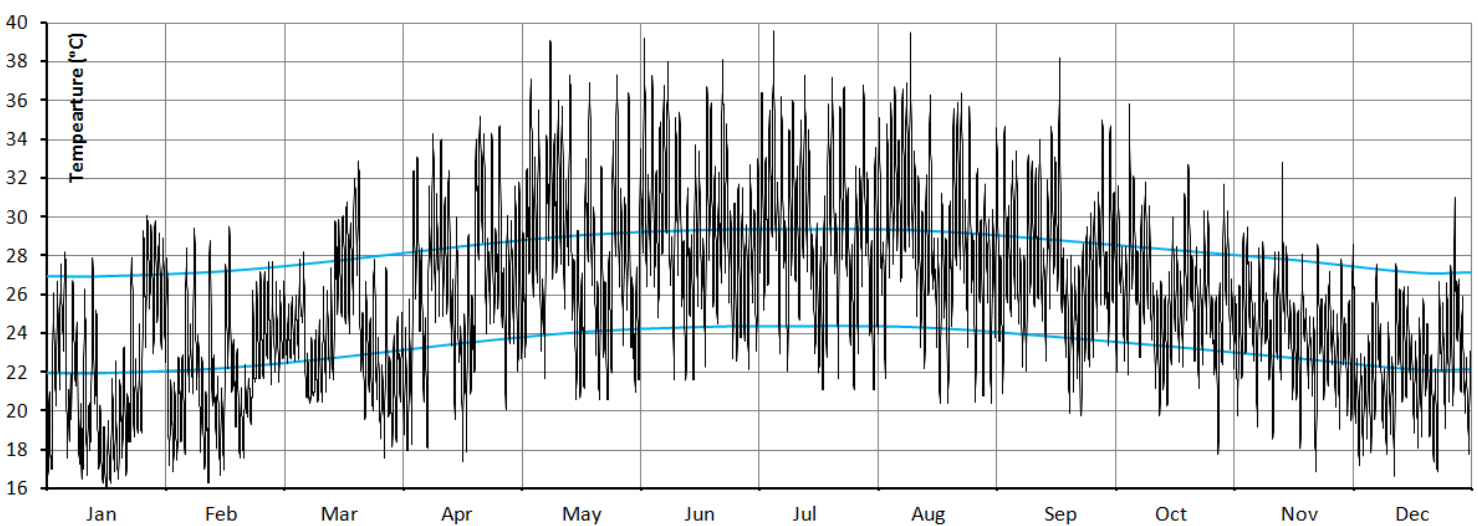

\subsection{The effect of different ventilation schemes}

Three other ventilation schemes, namely case A, B and C, were subsequently applied to examine their capability in improving comfort. Maximum ventilation flow rates were not changed, but opening controls were varied in summer and mild seasons. Mechanically assisted ventilation was employed in case $\mathrm{C}$ using an electrical ventilator which had the flow rate of $2500 \mathrm{~m}^{3} / \mathrm{h}$ (power $\left.60 \mathrm{~W}\right)$. More details of ventilation schemes are listed in Table 4. 
Simulated performances of case A, B and C were compared with that of reference case as shown in Table 4. It can be derived from case $\mathrm{B}$ that in mild seasons all day ventilation is a better choice, comparing with daytime ventilation. An important finding is that night ventilation in summer (case A) slightly improved comfort $(4.15 \%$ of a year) while mechanically assisted ventilation in summer (case $\mathrm{C}$ ) significantly did (18.08\% of a year). This may be explained by insufficient ventilation flow rate at night when external wind speed is usually at its lowest. In this case, low energy ventilation should be employed at night to maximise the cooling effect of night ventilation. However, it is worthy to note that night ventilation which requires the openings to be closed during daytime might cause some negative effects, e.g. indoor air quality and high humidity. Based on a long-term in situ measurement in Malaysia, Kubota et al. [12] mentioned that night ventilation strategy causes high humidity conditions during daytime which may interfere with occupants' comfort. Generally, adaptive comfort approach uses operative or air temperature as the unique criterion to assess thermal comfort, provided that adaptive actions are allowed. In reality, human response to the thermal environment is much more sophisticated and partly depends on the evaporative heat loss through the cooling effect of sweating which directly relates to the air humidity. The comfort results may change if other comfort models (e.g. steady-state model [13], two-node model [14], etc.) which include relative humidity in the assessment are applied. On the warm side of the comfort zone, higher relative humidity (over 60\%) would lead to worse thermal comfort indexes (predicted mean vote, PMV; effective temperature, ET*; standard effective temperature, SET*). In addition, very humid condition might cause mould growth, condensation, other impact on human respiratory system [12,15], endurance time of the subjects [17] and hygiene discomfort [3]. For these reasons, the present study recommends that night ventilation in hot humid climate should only be employed whenever daytime humidity control is available, for example: ventilation at low flow rate, dehumidifi-cation. Otherwise, other solutions should be considered.

Table 4 Ventilation scenarios of the reference case and comparative cases and their simulated performances.

\begin{tabular}{lllll}
\hline & \multicolumn{2}{l}{ Ventilation scheme } & \\
\cline { 2 - 5 } & Reference case & $\begin{array}{l}\text { Night ventilation in } \\
\text { summer (case A) }\end{array}$ & $\begin{array}{l}\text { Full-day ventilation in } \\
\text { mild seasons (case B) }\end{array}$ & $\begin{array}{l}\text { Night ventilation with mechanical } \\
\text { support - summer (case C) }\end{array}$ \\
\hline Summer & Full-day open & Night time open & Full-day open & $\begin{array}{l}\text { Daytime close, mechanical } \\
\text { ventilation at night }\end{array}$ \\
Winter & Full-day close & Full-day close & Full-day close & $\begin{array}{l}\text { Full-day close } \\
\text { Mild seasons }\end{array}$ \\
$\begin{array}{l}\text { Simulated result } \\
(\% \text { comfort of a year) }\end{array}$ & $61.63 \%$ & $65.78 \%$ & $68.43 \%$ & Full-day open \\
& & & & $79.71 \%$
\end{tabular}

Fig. 6. Hourly plot of indoor temperature on Brager's adaptive comfort model (reference case).

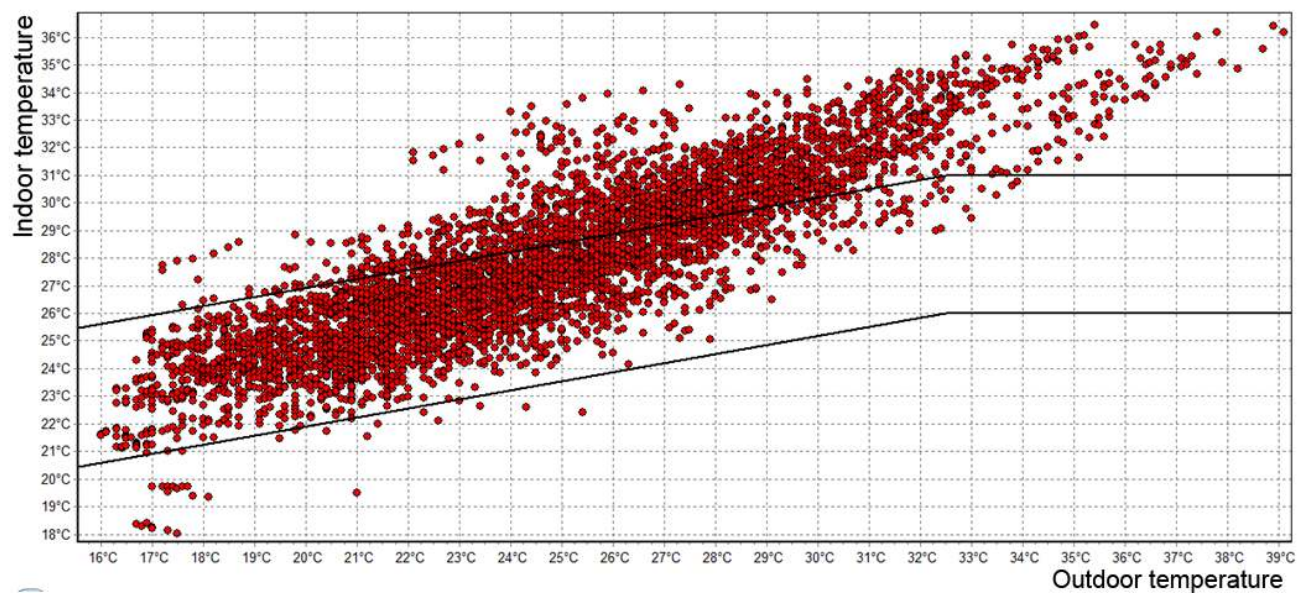




\subsection{The effect of the orientation of the apartment}

On each floor level, there are four similar apartments which are located at four corners of the building. Thermal performances of these apartments are, of course, unequal due to their different orientations. This study tried to outline these differences through which the best orientation can be derived. Eight possible orientations of the apartment were assumed as shown in Fig. 7. Two simulations were run, using all input data of the reference case except the orientation of the apartment. The thermal zone between these apartments was considered adiabatic. The simulated results are showed in Fig. 7. It is obvious that West oriented apartment was suffered from high solar radiation and had the lowest comfort (59.39\%). In term of thermal comfort, North-East oriented apartment was found to be the best (64.36\%). An apartment with appropriate orientation can considerably profit more comfort, up to $5 \%$ of a year. The above-mentioned results do not take the wind effect into consideration. In Danang city, the prevailing cool wind mainly blows from East sea while the cold wind comes from the North [16]. Therefore, the optimal orientation for this apartment may vary between the North-East and the East.

Fig. 7. Eight possible orientations of the apartment (left) and thermal comfort performance (right).
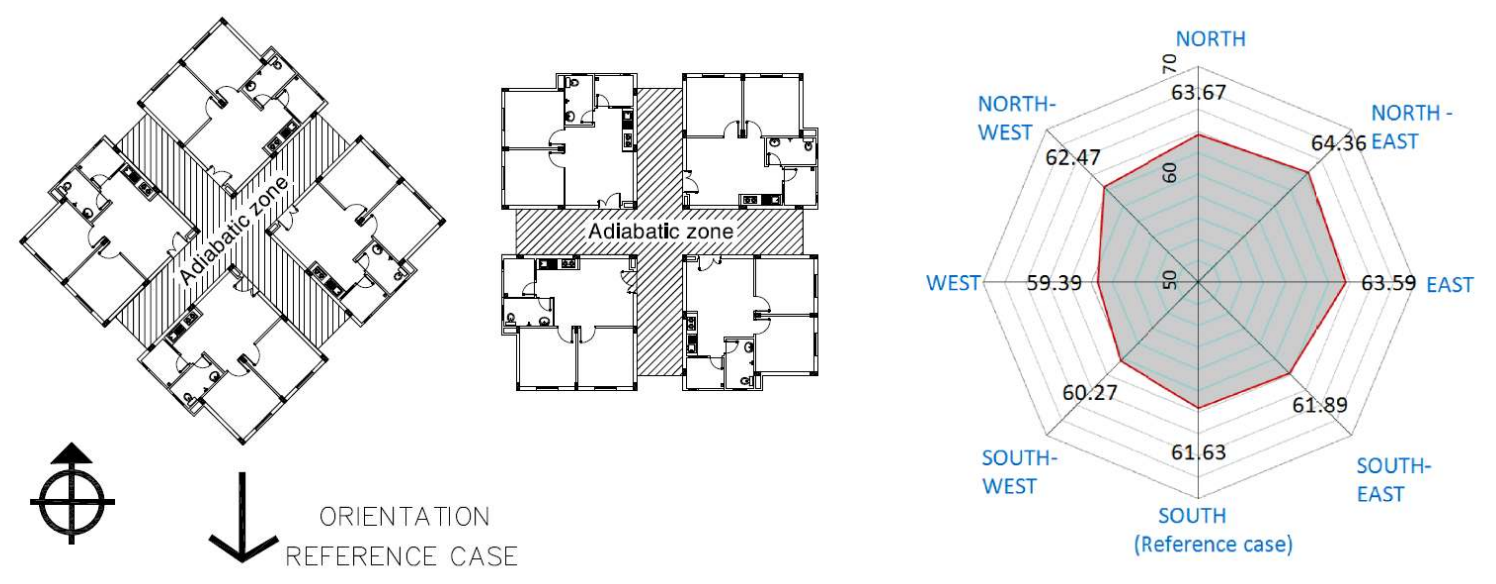

\subsection{The effect of other strategies comparing with reference case}

From the analyses of the reference case, it is clear that thermal performance of this apartment was not perfect since nearly $40 \%$ of a year were uncomfortable. Such low cost residential buildings are currently accepted by local poor residents due to their low expectation, but further improvements are very essential to meet their future demands. Consequently, various architectural strategies and the ir effectiveness in term of thermal comfort are examined and evaluated. They were related to the external walls' colour, size of external openings, insulation materials, solar shading and ventilation. Details of the strategies used and their simulated performances are presented in Table 5.

It may be obvious that the increase of glazing area (case I) and solar heat gain (case H) considerably reduces indoor comfort due to intense solar irradiation and high ambient temperature in Danang. As shown in Table 5, the use of thermal insulation in external walls (case D), surprisingly, did not give any improvement and thus was not necessary. This may be explained that the insulation material may partly reduce solar heat gain through external walls, but it considerably restricts the cooling effect of the cool air during night time. This hypothesis was strongly supported by the result of case $\mathrm{J}$ in which heavy thermal mass did not perform better than lightweight structure (comparing with case C). Therefore, in hot humid climate of Danang, lightweight envelops without insulation are sufficient and economic in maintaining human comfort, provide that they are well shaded. 
Table 5 Details of strategies used and their simulated performances.

\begin{tabular}{|c|c|c|c|c|}
\hline Strategies & Name & Description & $\begin{array}{c}\text { Result } \\
(\% \text { comfort })\end{array}$ & $\begin{array}{c}\text { Comfort } \\
\text { improvement? }\end{array}$ \\
\hline Insulation material & Case D & $\begin{array}{l}3 \mathrm{~cm} \text {-thick insulation was installed in the } \\
\text { core of external walls. This raises thermal } \\
\text { resistance of the wall from } 0.91 \text { to } 1.46 \\
\qquad \mathrm{~m}^{2} \mathrm{~K} / \mathrm{W}\end{array}$ & 61.13 & No \\
\hline Shading devices & Case E & $\begin{array}{l}0.8 \mathrm{~m} \text { shading devices were added above } \\
\text { all external windows }\end{array}$ & 64.53 & Yes $(2.90 \%)$ \\
\hline Low $U$-value windows & Case F & $\begin{array}{l}U \text {-value of external windows were } \\
\text { reduced (from } 4.77 \text { to } 2.76 \mathrm{~W} / \mathrm{m}^{2} \mathrm{~K} \text { ) using } \\
\text { 2-layer glazing }\end{array}$ & 62.55 & Yes $(0.92 \%)$ \\
\hline Brighter colour for external walls & Case G & $\begin{array}{l}\text { The current colour (bright yellow) of } \\
\text { external walls was replaced by white } \\
\text { paint which reduces solar absorptance } \\
\text { from } 0.29 \text { to } 0.24 \text {. Thermal emissivity } \\
\text { was almost unchanged }\end{array}$ & 62.58 & Yes $(0.95 \%)$ \\
\hline Darker colour for external walls & Case $\mathrm{H}$ & $\begin{array}{l}\text { The current colour (bright yellow) of } \\
\text { external walls was replaced by brown } \\
\text { paint which increases solar absorptance } \\
\text { from } 0.29 \text { to } 0.79 \text {. Thermal emissivity } \\
\text { was unchanged }\end{array}$ & 54.14 & No \\
\hline Resizing external windows & Case I & $\begin{array}{c}\text { Total area of external windows was } \\
\text { multiplied by } 2.25\end{array}$ & 58.36 & No \\
\hline Thermal mass and night purge & Case J & $\begin{array}{l}\text { Thickness of external walls was doubled } \\
\text { from } 20 \mathrm{~cm} \text { to } 40 \mathrm{~cm} \text {; ventilation scheme } \\
\text { of case } \mathrm{C}\end{array}$ & 80.68 & Yes $(19.05 \%)$ \\
\hline Combination of strategies & Case $\mathrm{K}$ & Combine case $\mathrm{C}, \mathrm{E}, \mathrm{F}, \mathrm{G}$ & 82.26 & Yes $(20.63 \%)$ \\
\hline
\end{tabular}

Reduction of solar heat gain on external walls by shading devices, using low $U$-value openings and brighter colour offered small comfort improvements. Nevertheless, comparison between case G (light colour external walls) and $\mathrm{H}$ (dark colour external walls) shows a significant disparity, confirming the importance of solar reflectance of building envelop. Our experiences also indicate that the effectiveness of each solution not only depends on their own settings, but also strongly related to building configurations, building operation and the climate. In our case, the apartment in question has only two external surfaces and two small windows.

Consequently, the effect of the solar irradiation on indoor thermal environment was relatively small. Therefore, minor improvements recorded in case A, B, E, F and G do not mean that these strategies should not be applied in the current climate condition. It seems unreasonable to impose any specific recommendation for all circumstances and thus the selection of building designs and building control requires experienced designers and their sensibilities as well.

Although case K showed the best performance, uncomfortable period still occupied about $18 \%$ of a year. As shown in Fig. 8, uncomfortable periods mainly dropped in three following conditions: extremely hot (129 h); slightly hot $(969 \mathrm{~h})$ and slightly cold $(292 \mathrm{~h})$. To completely eliminate these discomforts, we propose some additional solutions as listed in Table 6 .

The above-mentioned analyses and proposals indicate that the indoor environment of this apartment can theoretically achieve thermal comfort all year round without consuming much energy. Nevertheless, under hot humid climate of Danang, relying completely on passive solutions to maintain human comfort is hardly feasible. Similar finding [16], according to which 'under extreme conditions the building would benefit from low-energy mechanical systems, such as mechanically assisted ventilation, evaporative cooling, passive solar heating or occupants'adaptive responses such as clothing insulation, activities, opening controls and the use of fans', was also found in Hanoi, Vietnam.

A further comparative study was done. The main findings of the present study were compared with those of other authors to assess their reliability as shown in Table 7. Care must be taken in such comparison because of the differences in study background, climate classification and semantic content of the statements. In addition, there is no passive strategy which can be effectively applied all year round; and a unique strategy hardly gives 
the best performance. So the selected solution should be the best combination of the strategies, which requires expert knowledge and appropriate analysis tools (e.g. optimisation tool).

As can be seen in Table 7, the results of the present study generally matched with previous counterparts, confirming their reliability. Astonishingly, most previous studies did not mentioned in detail about ventilation strategies regardless of their significant effects on thermal environment. In fact, long term examination of ventilation strategies is hardly feasible without the aid of computer simulation which have been recently popularised. Noticeably, Koenigsberger did not highly appreciate cooling effect of night ventilation. He explained that in hot humid climate the ambient temperature remains almost the same throughout the day and night; a building thus cannot be cooled off sufficiently at night time to allow the storage of heat during the day. However, the studies of other authors [12,21] strongly confirmed night ventilation effect. In term of energy consumption, night ventilation significantly reduced cooling load with an average contribution possibly close to $12 \mathrm{kWh} / \mathrm{m}^{2} /$ year [22]. In brief, cooling effect of night ventilation is obvious although its applicability needs further investigation.

Fig. 8. Comfort result and analysis of case $K$ (combination of all positive strategies).

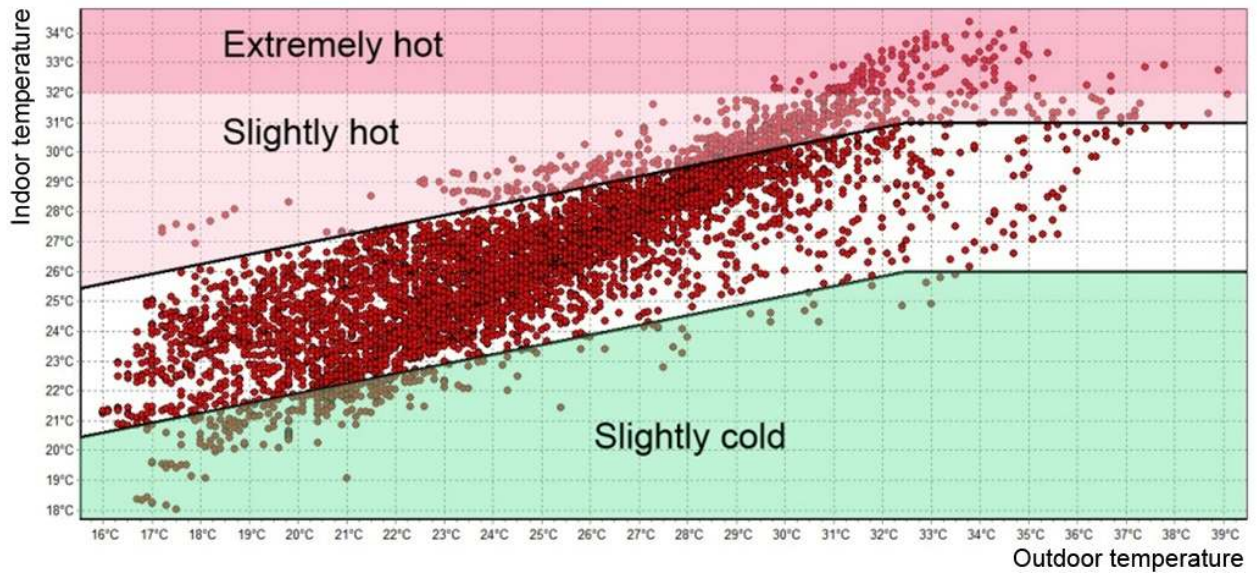

Table 6 Additional solutions to completely eliminate discomfort.

Indoor condition

Extremely hot (129 h) temperature exceeds $32^{\circ} \mathrm{C}$

Proposed additional solutions

Employing mechanical cooling, e.g. air-conditioning system

Estimated energy consumption
Slightly hot (969 h) temperature varies between $32^{\circ} \mathrm{C}$ and upper comfort boundary

Employing body cooling by fan, indirect or direct evaporative cooling by water vapour mist fan or natural wind

Small amount
Slightly cold (292 h) temperature drops below lower comfort boundary, but always above $18^{\circ} \mathrm{C}$

Wearing suitable cloths, adjusting alimentation regime, controlling openings, using passive solar energy for heating

None 
Table 7 Correlation between the main findings of the present study and other authors.

\begin{tabular}{lcccc}
\hline Main findings - present study & \multicolumn{4}{l}{ These findings agree with those reported by other authors? } \\
\cline { 2 - 5 } & Givoni [17] & Olgyay [18] & Koenigsberger et al. [19] & Szokolay [20] \\
\hline Thermal mass is not essential & Fully agree & Fully agree & Fully agree & Fully agree \\
Wall insulation is not needed & Partly agree & Partly agree & Partly agree & - \\
$\begin{array}{l}\text { High reflectance external surfaces } \\
\text { Glazing area subjected by the sun should be }\end{array}$ & Partly agree & Fully agree & Fully agree & Fully agree \\
$\begin{array}{l}\text { avoided } \\
\text { Shading devices are needed }\end{array}$ & - & Partly agree & Fully agree & Fully agree \\
$\begin{array}{l}\text { Full-day ventilation in mild seasons } \\
\begin{array}{l}\text { Cooling by night ventilation in summer } \\
\text { performs better }\end{array}\end{array}$ & Fully agree & Fully agree & Fully agree & - \\
\hline
\end{tabular}

\section{Conclusion}

An investigation on thermal performance of a naturally ventilated low cost apartment in hot humid climate of Danang has been done using an in situ measurement and COMFIE computer simulation tool. Suitable inputs for the simulation were imposed based on the result of a series of calibrated runs which reinforced the simulated results. The statistical indicators of the "goodness-of-fit" between simulated and measured temperature were forced to decrease to an acceptable limit.

The comfort period in the apartment obtained from the study only occupied about $61 \%$ of a year. Since the building is naturally ventilated, for nearly $39 \%$ of a year the occupants would feel uncomfortable, revealing that significant improvements are needed.

In term of thermal comfort, night ventilation in summer and full-day ventilation in mild seasons were found effective since their improvements were $4.15 \%$ and $6.80 \%$ of a year, respectively.

Mechanically assisted night ventilation in summer was proved to be the most effective solution with an improvement of $18.08 \%$. However, the concern of energy consumption and indoor air quality during daytime may impede its widespread application.

Through the simulated results and comparative study, other solutions were also found effective and applicable, including: apartment orientation, the use of high reflectance building envelops, shading devices, low $U$-value openings and the reduction of glazing area, although their performances were fairly small. In contrast, thermal insulation and high thermal mass did not have any positive contributions on the thermal environment.

It is worthy to note that this apartment can theoretically achieve thermal comfort all year round without consuming much energy. This is an important scientific basis for the development of energy-saving housing, proceeding to energy independent models in hot humid climate of Vietnam.

The present study has some limitation as it was carried out on an apartment oriented to the South on the 3rd floor. In a high-rise condominium, indoor wind condition strongly depends on the apartment's altitude since the horizontal wind velocity increases as a logarithmic function of height. More studies are therefore needed to examine the influence of orientation and altitude on simulated results. Through this study, night ventilation with or without mechanical assistance still raises some interesting questions about indoor air quality, energy consumption comparing with mechanical air conditioned. Also, when the apartment is closed the inverse effect of humidity on the result of comfort analysis needs further quantitative assessment. Night ventilation is clearly a promising direction for the next research.

\section{Acknowledgements}

This study was financially supported by the Ministry of Education and Training of Vietnam (Grant no. 624/QDBGDDT: 9th Feb. 2010) and partly by Wallonie Bruxelles International (Grant no. 23478/AMG/BE.VN/JP/jp).

\section{References}

[1] Danang People's Committee, Danang low cost housing policy (in Vietnamese). Available at http://www.danang.gov.vn (accessed 
Published in: Energy and Buildings 47 (2012) 237-246

Status: Postprint (Author's version)

05.05.2011).

[2] J.D. Bronson, Calibrating DOE-2 to weather and non-weather dependent loads fora commercial building, M.S. thesis, Energy system Report No. ELS-TH-92/04-01, Texas A\&M University, College Station, TX, 1992.

[3] ASHRAE, ASHRAE Handbook of Fundamentals, ASHRAE, Atlanta, 2009.

[4] ASHRAE, ASHRAE Guideline 14-2002, Measurement of Energy and Demand Savings, ASHRAE, Atlanta, 2002.

[5] T.E. Bou-Saada, J.S. Haberl, An improved procedure for developing a calibrated hourly simulation models, in: 4th International Conference Building Simulation '95, International Building Performance Simulation Association, August 14-16, 1995.

[6] D.E. Claridge, N. Bensouda, S.U. Lee, G. Wei, K. Heinemeier, M. Liu, Manual of procedures for calibrating simulations of building systems, Report HPCBS\#E5P23T2b, October, 2003.

[7] Izuba energies, Pleiades-Comfie software. Available at http://www.izuba.fr (accessed 7.04.10).

[8] B. Peuportier, Bancs d'essais de logiciels de simulation thermique, Journée Thématique SFT-IBPSA (2005).

[9] G.S. Brager, R. de Dear, A standard for natural ventilation, ASHRAE Journal October (2000).

[10] R. de Dear, G. Brager, D. Cooper, Developing an Adaptive Model ofThermal Comfort and Preference, Final report - ASHRAE Project RP-884,1997 (available at: http://sydney.edu.au/architecture/documents/staff/richard_de_dear/RP884_Final_Report.pdf (accessed 20.06.11))

[11] ASHRAE, ASHRAE Standard 55, Thermal Environmental Conditions for Human Occupancy. ASHRAE, Atlanta, 2004.

[12] T. Kubota, D. Toe Hooi Chyee, S. Ahmad, The effects of night ventilation technique on indoor thermal environment for residential buildings in hot-humid climate of Malaysia, Energy and Buildings 41 (2009) 829-839.

[13] P.O. Fanger, Thermal Comfort - Analysis and Applications in Environmental Engineering, McGraw-Hill, New York, 1970.

[14] A.P. Gagge, J. Stolwijk, Y. Nishi, An effective temperature scale based on asimple model of human physiological regulatory response, ASHRAE Transactions 77 (1) (1971) 247-262.

[15] The US Department of Defense, Cooling Buildings by Natural Ventilation (UFC 3-440-06N), 2004.

[16] A.T. Nguyen, Q.B. Tran, D.Q. Tran, S. Reiter, An investigation on climate responsive design strategies of vernacular housing in Vietnam, Building and Environment 46 (2011) 2088-2106.

[17] B. Givoni, Man Climate and Architecture, Elsevier Publishing Co. Ltd., Oxford, 1969, pp. 320-328.

[18] V. Olgyay, Design with Climate, Princeton University Press, New Jersey, 1963, pp. 172-177.

[19] O.H. Koenigsberger, T.G. Ingersoll, A. Mayhew, S.V. Szokolay, Manual of Tropical Housing and Building, Longman Publisher, New York, 1973, pp. 213-220.

[20] S.V. Szokolay, Introduction to Architectural Science, Elsevier Science, Oxford, 2004, pp. 68-69.

[21] G. Carrilho da Gracia, Q. Chen, LR. Glicksman, L.K. Norford, Simulation of wind driven ventilative cooling systems for an apartment building in Beijing and Shanghai, Energy and Buildings 34 (2002) 1-11.

[22] M. Santamouris, A. Sfakianaki, K. Pavlou, On the efficiency of night ventilation techniques applied to residential buildings, Energy and Buildings 42 (2010) 1309-1313. 


\section{Appendix A}

Thermal zones: no heating-cooling device or other electrical and human heat sources (unoccupied apartment)

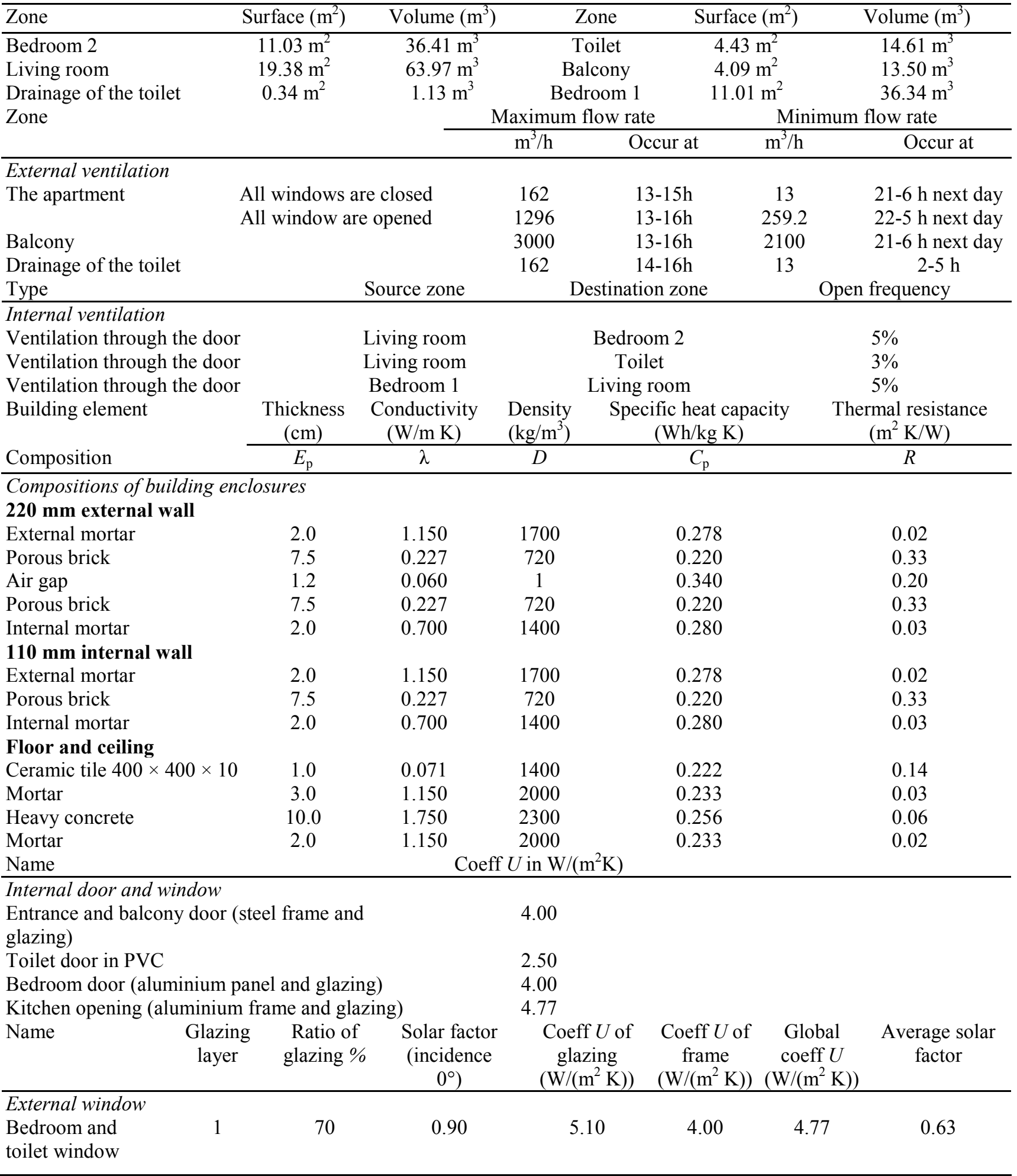

